\title{
ORGANIZATIONAL TRUST BETWEEN INSTITUTIONAL AND INTERPERSONAL TRUST
}

\author{
Raluca RUSU \\ rbalasoiu@yahoo.com
}

\author{
Alexandru BABOŞ \\ babos.alexandru@yahoo.com
}

"NICOLAE BĂLCESCU" LAND FORCES ACADEMY, SIBIU, ROMANIA

\begin{abstract}
This paper presents organizational trust as antecedent for organizational effectiveness. The main discussed problem, after trust perspectives interpretation presentation (rational and identification), is linked to the way in which trust can be built in organizations by managers, starting from managing the interpersonal trust.
\end{abstract}

\section{Keywords}

Organizational trust, institutional trust, interpersonal trust

\section{Introduction}

In the last years the researches dedicated to the role of trust in the organizational context have expanded considerably. The explanation resides in the fact that organizational trust is seen as an indicator of organizational health, one of the directly or indirectly determinants (moderating effect) of organizational efficiency.

Working together implies interdependence; people depend on each other when they have to fulfill a series of personal and organizational goals. Given this aspect, several theories have tried to describe the mechanisms for minimizing risk in labor relations. These theories support the idea of compliance in organizations precisely to avoid the consequences of trust infringement. Even though many organizations use control mechanisms instead of promoting trust between work relations, the composition of today's workforce suggests that the importance of organizational trust will certainly increase. One aspect that cannot be ignored is the human resource diversity. Mayer, Davis \& Schoorman (1995) point out that the increase of workforce diversity implies that people with different backgrounds come in contact and can rely less on similarities and shared experiences in order to increase a mutual attraction and desire to work together. In this context developing mutual trust provides a mechanism that allows people to work together more effectively. Another trend related to organizational changes leading to increased interest in the study of trust is related to the increasing implementation within modern organizations of a participative leadership style and selfconducted work teams [1]. 
These are only two arguments which support the idea that the construction of organizational trust is a necessity in the context of the current organizational changes.

Next we will try to define the concept of organizational trust by presenting its analysis dominant perspectives.

\section{Perspectives in the Analysis of Organizational Trust}

The concept of trust was launched long ago in social sciences literature, but its direct applicability at the organizational problem is relatively recent.

In the specialty literature there are numerous definitions, making it difficult to develop a unified and coherent picture of the phenomenon, but we can still identify some trends defining the organizational trust that enroll actually in the great patterns of interpretation of social trust. Before we present the dominant perspectives of trust analysis, we can say that organizational trust is the overall assessment of how the organization is perceived as trustworthy. "It is the feeling of belief that the organization will perform her actions are beneficial or at least not against his or her" [2].

\subsection{The Rational Perspective in the Analysis of Organizational Trust}

Depending on the used theoretical approach, the existing studies about trust can be classified into two categories, categories that can be extrapolated to the level of organizations. Thus, Lewicki \& Bunker (1996) given the level of trust which has been cultivated in an interpersonal relationship have described two basic forms of trust: trust based on calculation and trust based on identification.

For a long time the rational choice perspective and the trust-based calculation have been the most influential theory in terms of trust and understanding its implications. Therefore, trust is defined using the terms of rational choice theory as "introducing risk into the decision to act or not" [3]. To have trust, or not, is the result of a rational calculation based on all available information. The trust based on calculation means that people decide to have trust convinced that they will not be deceived. Simply it is about the awareness of benefits brought by a trustworthy behavior.

Also, Rousseau et al (1998) speaks of trust calculation form and of trust relational form. The author believes that the trustbased on calculation form is based on "rational choices and specific interactions involved in economical exchange, choices which are guided by rational calculation of costs and benefits" [4].

\subsection{The identification perspective in} the analysis of organizational trust

The second form, the trust-based on identification, develops as people come to understand that they share the same beliefs and values, a kind of mutual attraction, after which everyone will feel that the other would protect their interests In light of this perspective, trust is understood as a combination of values, attitudes and beliefs shared by the members of a population. Many theoretical and empirical studies define trust by using this approach, among them the most important being Putman (1993), Fukuyama (1995), Sztompka (1999).

Giddens (1991) argues that without trust, the individual should examine in detail each interaction with the environment, which could lead to failure of the individual to act. For example the full involvement of the state in all areas of society during the communist regime, provided a significant reduction of risks associated with everyday life. This aspect is also true in organizations with an authoritarian management system, characterized by a high uncertainty avoidance (in terms of G. Hofstede), lack of ambiguity tolerance and lack of need of formal rules. But democracy rules have changed and the new rules demanded withdrawal of the state from society, which put the individual in the position to face a number of risks. In modern organizations, where subordination relations are increasingly being replaced by 
relations of collaboration in achieving organizational goals, interactions between individuals must rely on good faith, honesty in transactions and limited opportunism, meaning on trust mostly [5].

A growing number of researchers have overcome the notion that people have their trust based on a rational calculation of costs and benefits. Adherents of this view refer to the dynamic relationship between the one who trusts and the trust which it is granted, well as the conditions that define this relationship (Mayer, Davis and Schoorman, 1995; Rousseau et al, 1998). What is emphasized is the procesual and dynamic nature of trust. Mayer, Davis \& Schoorman (1995) argues that trust should be conceptualized not only as a calculative orientation towards risk, but also as a social orientation towards people and society as a whole. When people do not have the knowledge or necessary experience in trusting others, organizational trust, it must be negotiated individually or is mandatory to find substitutes for it. These substitutes can be in the form of contracts or other administrative procedures which are expensive and time consuming for organizations.

Culbert and McDonough (1986) states that it is very important for managers to realize that the functioning of an organizational system depends greatly on the internalization of a predefined set of goals, values and predispositions. The same authors have conceptualized the process of internalizing as commitment towards the dominant reality of the system. The internalization gives to the organization members the possibility to act spontaneously and decisive in order to support the system, without having a debate on each action opportunity. From the perspective of the authors, employees who choose to trust the organization internalize their goals, assumptions, and organizational values. In contrast, employees who do not trust the organization/system, it is considered that they had not gone through this process of internalization. Culbert and McDonough
(1985) define trust in the system as the availability of individuals to internalize the viewpoints of the system, because this will protect them and recognize their contributions to achieving the organization's goals [6].

\section{Institutional Trust and Interpersonal Trust}

To see how we build organizational trust is important to distinguish between two types of trust, depending on its purpose: institutional trust and interpersonal trust.

Sztompka (1999) believes that institutional trust cannot be easily separated from interpersonal trust. On the one hand we talk about other individuals to whom we can turn trust and in this case we speak of interpersonal trust and on the other hand we talk of institutional trust, including trust in the various systems. Confidence interpersonal relationships involves face-to-face relations, while the target institutional trust has to be oriented towards social objectives such as institutions, organizations etc. Sztompka, "argues that beyond these social objects are the people whom they're invested with confidence, even if we do not know them and we only have second hand information about them" [7]. The author exemplifies this way: "when I decide to fly with Lufthansa from Tokyo implies that I trust the company's pilots and other members of the crew, the technicians, inspectors, supervisors and so on. No need to personally know all of them to make myself a picture of them shaped on the basis of other sources (e.g. stereotypes about the German accuracy and efficiency, based on references from friends, etc.)" [8]. The illustration provides an excellent example of why the author believes that the distinction between interpersonal and institutional trust is unclear.

To summarize Sztompka's statements, trust in people is at the basis of all types of social trust, whether we speak about the institutional trust or interpersonal trust.

Dependence relationship between the two types of trust is supported by many other authors, such as Dasgupta (1998) 
which believes that if confidences in an organization waver, then we will not have confidence that people will fulfil their contractual obligations and thus we will not create these contracts. Exactly these links are the ones that make a good confidence so fragile. Erosion in any part of this mosaic destroys the whole mosaic [9]. Trust in an institution may be extended towards the members of that institution, and by extension, the group from which they come.

Starting from these studies we can say that the low confidence in colleagues, managers, etc. can turn into low trust in the organization. For example if we refer to Romania, where in general predisposition for interpersonal trust is relatively low, according to the latest wave of World Value Survey study, Wave 6 2010-2014 (specifying that the difference up to $100 \%$ is given by NR and NS) (see table 1) we can affirm that the institutional confidence has suffered, and the human resource management need to work hard in order to build the organizational trust. The question used in this study is: I'd like to ask you how much you trust people from various groups. Could you tell me for each whether you trust people from this group completely, somewhat, not very much or not at all?

As can be seen in the table, in Romania the highest confidence and trust is in the family, compared to other categories of people in which is not very high. In context in which the diversity of labor force will be growing, we need to find ways to increase organizational trust, and these are related to human resource management.

Interpersonal trust

Table no. 1

\begin{tabular}{|c|c|c|c|c|}
\hline & $\begin{array}{c}\text { Trust } \\
\text { completely }\end{array}$ & $\begin{array}{c}\text { Trust } \\
\text { somewhat }\end{array}$ & $\begin{array}{c}\text { Do not trust } \\
\text { very much }\end{array}$ & $\begin{array}{c}\text { Do not trust } \\
\text { at all }\end{array}$ \\
\hline Family & $80.5 \%$ & $16.3 \%$ & $1.9 \%$ & $0.8 \%$ \\
\hline Your neighborhood & $8.8 \%$ & $33.5 \%$ & $43.3 \%$ & $13.2 \%$ \\
\hline People you know personally & $9.7 \%$ & $45.0 \%$ & $35.6 \%$ & $8.5 \%$ \\
\hline People you meet for the first time & $0,8 \%$ & $6.7 \%$ & $44.9 \%$ & $44.9 \%$ \\
\hline People of another religion & $1,7 \%$ & $18,1 \%$ & $46,2 \%$ & $23,9 \%$ \\
\hline People of another nationality & $1,8 \%$ & $18,4 \%$ & $44,9 \%$ & $25,5 \%$ \\
\hline
\end{tabular}

4. Factors which Influence Organizational Trust

Definitely, confidence is crucial for those in leadership positions. Tyler \& Degoey (1996) remark that the ability of authorities to manage effectively will suffer if constantly should explain and justify their actions. It is also too expensive and impractical to monitor the performance of subordinates. Managers cannot see and punish every act of disobedience, nor recognize and reward every act of cooperation. The authors show that individuals are more likely to accept organizational decisions when they have confidence in management actions, even when actions are not conducive to individuals [10].

What could increase the organizational trust? Creed and Miles (1996) believes that there is a link between organizational structures and trust, link moderated by the existing control in the organization. Thus, given that the control varies from one organization form to another on a continuum, where at one end is entrepreneurial structure (or simple structure in terms of H. Mintzberg) where control is very high and confidence is low and at the other end is organizing network, which is related on the basis of mutual trust, managers are well advised to rely on collaboration and not on those of subordination because they favor developing confidence [11].

Knowledge of the organizational roles is another trusted source. An organizational climate in which employee roles clarity and visibility is important should be promoted in 
order to develop trust. Also, policies for assessing performance and reward may be a way to encourage trust when rewarding performance procedures are aimed towards principles of procedural justice.

The organizational culture shapes the behavior of members, thus different authors sought to identify the values that encourage trustworthy behavior. The organizational culture of trust in the organization involves manifestation of support, advice, listening; caring for each other, promoting clear values and norms, all common (Whitener et al 1998). Values sharing is the first step through which people are experimenting the highest form of trust, namely the unconditional trust. When organizations cannot rely on this congruence of values, management must introduce and use a reliable form of impersonal, calculative trust with precise contractual clauses [12].

Another direction of management that can increase trust is to encourage the participation of employees in decision making, which shows that a participative leadership style is favorable for building an organizational climate based on trust. The literature devoted to the study of organizational trust, it emphasizes the importance the self-lead teams because control mechanisms are reduced, and trust takes the place of supervision. How can managers create an organizational climate in which people trust each other? The answer is complex: to communicate, which means talking and listening, to have a supportive conduct, by showing mutual respect, honesty, openness, consistency, fairness.

\section{Conclusion}

It clearly appears that trust is a functional precondition needed to reduce the complexity of the world/organization and to facilitate adaptation through an increase of interaction [13] because trust succeeds where rational prediction alone would fail [14].

Surely the interest in trust is due to an urgent awareness that the foundations for social cooperation, solidarity and consensus have been eroded and therefore need to seek new alternatives.

\section{References}

1. Mayer, Roger; Davis, James and Schoorman, David "An integrative model of organizational trust", Academy of Management Review, Vol.20, No.3, (1995): 710.

2. Tan, H. H., and Tan, C. S. F. (2000). "Toward the differentiation of trust in supervisor and trust in organization". Genetic, Social and General Psychology Monographs, 126, 243.

3. Coleman, James Samuel, Foundations of Social Theory, (Cambridge: Harvard University Press, 1990), 61.

4. Rousseau, D.; Sitkin, S.; Burt Ronald and Camerer, C. "Not so Different after all: A Cross-Discipline View of Trust", Academy of Management Review, Vol.23, No.3, (1998): 400.

5. Cummings, L.L., and Bromiley, P. "The Organizational Trust Inventory (OTI): Development and validation", in Trust in organizations Thousand Oaks, R. Kramer, \& T. Tyler (Eds.), 303, (CA: Sage, 1996).

6. Culbert, S.A. and McDonough, J.J., Radical Management: Power Politics and The Pursuit of Trust, (New York, NY: The Free Press, 1985): 177.

7. Sztompka, Piotr, Trust: A sociological Theory, (Cambridge University Press, 1999): 41.

8. Ibidem. 
9. Dasgupta, Partha „Trust as a Commodity” in Trust: Making and Breaking Cooperative Relations, Diego Gambetta and Basil Blackwell ed., (New York, 1988): 50

10. Tyler, T.R. and Degoey, P., "Trust in organisational authorities: the influence of motive attributions on willingness to accept decision", in Trust in Organizations: Frontiers of Theory and Research, Kramer, R.M and Tyler, T.R. (Eds), (Thousand Oaks: Sage, 1996): 331-56.

11. Creed, W.E., and Miles, R.E., "Trust in organizations: A conceptual framework linking organizational forms, managerial philosophies and the opportunity costs and controls" in Trust in Organizations: Frontiers of Theory and Research, Kramer, R.M and Tyler, T.R. (Eds), (Thousand Oaks: Sage, 1996).

12. Ellen M. Whitener, Susan E. Brodt, M. Audrey Korsgaard and Jon M. Werner, „Managers as Initiators of Trust: An Exchange Relationship Framework for Understanding Managerial Trustworthy Behaviour", The Academy of Management Review, Vol. 23, No. 3 (July, 1998): 513-530.

13. Rusu Horaţiu and Bălăşoiu Raluca, „Generalized trust - an imagined trust?” in European Integration from East to East: Civil Society and Ethnic Minorities in a Changing World, Horatiu, Rusu and Bogdan, Voicu. (coord.). (Sibiu: Psihomedia, 2005):100.

14. Lewis, D. and Weigert, A. "Trust as a social reality", Social Forces 63:4, (1985): 967 985. 